Journal of Education and Vocational Research

Vol. 3, No. 6, pp. 193-198, June 2012 (ISSN 2221-2590)

\title{
Lebanese University Institutional Repository Proposal
}

\author{
Khayrazad Kari Jabbour \\ Lebanese University, Hammana, Lebanon \\ karijabbour@hotmail.com
}

\begin{abstract}
This article addresses the need to establish an Institutional Repository at Lebanese University in Lebanon to facilitate the collection, preservation, and dissemination of the intellectual output of the students, faculty, and administrative officers of the University. This proposal for a prototype Institutional Repository (IR) offers the Lebanese University a means to enhance digital archiving and repository services for the University Library community.
\end{abstract}

Keywords: Open Source, Institutional Repository, DSpace, Open Source Software

\section{Introduction}

The world is becoming increasingly dependent on digital technologies. It has become crucial for Lebanese University to embrace technology in order to make the materials more accessible to students and faculty as well as to the public. It is very important for Lebanese University to take a leading role in managing and disseminating digital resources created by the institution and its community members. Clifford describes the institutional repository as "a set of services that a university offers to the members of its community for the management and dissemination of digital materials created by the institution and its community members. It is most essentially an organizational commitment to the stewardship of these digital materials, including long-term preservation where appropriate, as well as organization and access or distribution" (Clifford, 2003). An institutional repository can serve the university library goals including, but not limited to, the following activities: a. storing the university scholars' publications in one central database in order to provide easy access to this information. Shulenburger explained, "The job of digital repositories is to ensure that the extremely valuable scholarly or creative products that have been paid for by the public or by donors are ultimately accessible to them, as well as to students, faculty and researchers everywhere" (Shulenburger, 2008). b. Promoting the university by making scholars and faculty publications accessible to an online worldwide audience. This generates stable and reliable records for the researcher, managed and stored in ways, which meet international technical standards. c. Supporting students' accomplishments by providing access to their dissertations and research papers to online audiences. Most importantly, this serves as a longterm preservation of digital content.

\section{The Role of Institutional Repositories}

The institutional repository (IRs) is currently one of the most controversial issues within the library and open access $(\mathrm{OA})$ communities. Institutional repositories are not a recent development. Over the past year, there has been diverse vision about the role of institutional repository (IR) within the academic institution. Two main philosophical ideas flourished in a quest to explain the function of institutional repositories and their future. The first one describes institutional repositories as a replacement for traditional publishing and encourages academics to publish in open access repositories, which will reduce access limitations imposed by commercial publishers. In contrast, the other idea describes institutional repositories as supplements for traditional publications since they are not specialized journals but a collection of articles gathered from different disciplines and different periods. The representatives of this idea consider that institutional repositories best fit the grey literature (pamphlets, bulletins, visual conference presentations, etc.) that are not distributed or indexed by commercial or traditional publishers. Yet, after less than a decade of implementing institutional repositories in universities mainly in Europe and the United States, the experience proved to be not very successful at attracting scholars' articles since faculty were not encouraged to 
participate for reasons that will be discussed later. On the other hand, grey literature that was not distributed or indexed by commercial or traditional publishers has become the main content of many institutional repositories.

\section{Benefits for the University and Faculty}

There are many reasons for academic communities to use institutional repositories. The permanence of materials deposited in an institutional repository is very appealing to faculty members since personal websites can change or expire and data created with certain software will became unreadable in the future. In addition, increasing digitization, both in terms of document format and kinds of storage media, offers permanent access to information in the future. Rapid dissemination of articles is a very important reason for faculty members in scientific fields to use institutional repositories. Many publishing scholars have a timeline of when they plan to publish drafts or reports of their research results $s_{2}$ and an institutional repository is the best way to do so. In addition, many scientific researchers who work on the same topic are in a continuous race to publish first; by depositing early results of their research into an institutional repository, they ensure that they will be recognized as the progenitor of a new idea. In addition, an institutional repository is an excellent indicator of a university's academic quality ${ }_{2}$ and it increases the impact of faculty research by making their publications accessible locally to the university community through federated search or more widely through internet search engines. Finally, an institutional repository can replace e-reserve databases, and students will benefit from accessing class materials easily by searching the repository.

Faculty Concerns: There are some concerns and misunderstandings that make faculty and scholars hesitate to participate in an institutional repository project. The main concern for faculty is copyright issues. Copyright laws are very confusing and interpretations are usually based on precedence. Therefore, faculty are very cautious when it comes to copyright issues ${ }_{2}$ and some of them prefer not to deposit anywhere outside the original publisher's website (Davis, 2007). In addition, some scholars have the tendency not to use any new technology if it does not offer any benefit that affects them directly. Preprint deposit into a repository is also a big area of confusion for faculty. Faculty and scholars are worried about their papers not being published if deposited in an institutional repository prior to publication. Moreover, the quality of publications cannot be controlled in open access databases and institutional repositories. Many faculty and scholars are concerned about the association of their publications with low quality materials that may also be available in repositories. Some scholars and professors especially in scientific fields are worried about the absence of accuracy that may occur mainly with preprint publications.

Content and Accessibility: The advantage of an institutional repository is that it contains a wide range of digital materials stored in one centralized database and accessible to everybody without restrictions. Therefore, an institutional repository can house all digital holdings in the library that include but are not limited to dissertations, theses, picture collections, manuscripts that do not have copyright issues, music and video files, center and institute publications, university publications, and extension publications. In addition, an institutional repository can also house students' research and honors papers as well as preprints and research reports. However, the skeleton of an institutional repository is made up of the faculty refereed publications and conference proceedings for which it was created. The repository can also include reserve materials that need to be accessed regularly by students for courses.

Copyright \& Legal Issues: Copyright issues are considered the major limitation for faculty who are interested in depositing their publications to an institutional repository, since they are vague and regulations differ from one publisher to another. Some publishers allow authors to deposit the publisher version of their articles in an institutional repository for free and without an embargo period, while other publishers allow authors to deposit the publisher version of their articles in an institutional repository after an embargo period from 6 months to 5 years, and still other publishers issue permissions on a case by case basis. There are a few available tools for checking copyright permissions such as SHERPA's Romeo website where publisher policies can be searched and details related to their copyright regulations provided. Yet, not all publishers are listed on the site ${ }_{2}$ and in many cases permissions should be acquired by contacting the concerned publisher directly. Faculty should be encouraged to keep an non-exclusive right to their articles ${ }_{2}$ 
which will allow them to deposit in an open access repository, increase access to their research for educational purposes, give the research a wide exposure and increase its impact, and distribute copies of articles to classes or colleagues. The SPARC Author Addendum "is a legal instrument that modifies the publisher's agreement and allows [authors] to keep key rights to [their] articles" (SPARC, 2009). Publishers have become aware of the rise of open access repositories ${ }_{2}$ and they are being lenient with authors by signing copyright agreements that give them a non-exclusive right to deposit articles in their university's institutional repository. Yet, publishers retain the rights of: receiving proper citation as journal of first publications, getting financial return from published articles, and having the right to migrates articles to different formats in the future and to include them in their collections.

\section{Recommendations}

In order to guarantee a direct profit from the implementation of an institutional repository at Lebanese University, I recommend that librarians begin by depositing the collections that they own such as theses, dissertations, digital pictures, manuscripts, University publications, bulletins, and reports as well as documents that don't require copyright permissions such as students' research papers, unpublished articles, old articles, and old book chapters. By depositing all these publications into the repository, the library guarantees the dissemination and digital preservation of the university publications, which will also increase the university visibility on the local and international scale. The deposit of faculty-refereed articles into the repository should not be left to faculty members. Even though many faculty members are motivated and enthusiastic about the idea, getting copyright permissions and depositing articles into the database are both labor intensive and confusing, and many faculty members will feel discouraged about this job. Library staff will be responsible for getting copyright permissions and downloading articles with relevant metadata into the repository. The librarian in charge should make sure to introduce the service to faculty members and encourage them to send their publications to the library in order to prepare them and deposit them into the repository. The librarian should also assure faculty members that they do not have to worry about copyright issues and that the library will follow all procedures required to make sure that copyright laws are not violated. A license agreement that permits the library to deposit a specific publication into the repository should be signed by the author or the copyright holder. The repository can also include bibliographical citations for articles for which the library cannot acquire their copyright permissions with a link to the Document Delivery Service to order articles through it. A part in the repository should be dedicated to faculty and student profiles with links to their research papers; this will give them exposure and help them in their future careers.

Implementation: The implementation phase consists of nine steps: assembling a project committee; creating a schedule and timeline; conducting a needs assessment; developing a service definition; drafting policies and procedures; choosing and implementing software, staffing and training; depositing existing collections, marketing the product; and running the service.

Project Committee: After securing approval from the administration to begin the project, the first step is to assemble a committee. The committee should be headed by a project manager whose job is to plan, conduct, and supervise the implementation of the institutional repository from A to Z, which includes establishing contacts with faculty, drafting license agreements, preparing policies and procedures, and supervising all implementation stages. It is preferable that the librarian who manages the project be appointed to run the service in the future since he/she will acquire extensive experience during the implementation period. In addition to the Institutional Repository (IR) Librarian, the committee should be composed of the IT Librarian for advising on technology and platforms, the Archives Librarian for advising on collections and formats, the Information Services Librarian for marketing, and the University Librarian for staffing and funding issues.

Schedule and Timeline: The table below details the steps to be executed at every stage. The project committee will decide on the time needed to fully implement each step depending on many factors such as funding and staffing issues. 
Needs Assessment: An electronic survey shall be distributed to faculty members and students to investigate their needs and hopes from the service. The results of the survey will be taken into consideration when developing the service definition and drafting policies. The aim of the survey is also to find the level of understanding among faculty members of the services offered by the repository and to correct misunderstandings when marketing the service. Moreover, the survey itself is an early marketing tool of the repository.

Service Definition, Policies, and Procedures: The project committee should work on developing a service definition that indicates the purpose of the repository, its benefits, and the targeted audiences. The service definition should also delineate confusing issues such as copyright and highlight different services. Moreover, a service definition should contain explanatory information about the service and how to use it, such as how to deposit articles into the repository. Contact details are very important and should be available for additional help and advice on technical problems and other issues. Policies and procedures are the core content of the service definition. Any policy to be created should answer the following questions:

- What is the repository's mission?

- What types and formats of contents should we accept?

- Who are the major users of the service?

- Who are the key stakeholders?

- What services can be offered ideally, and what we afford to offer?

- What are the priority services?

Procedures should cover operational functions as well as service functions. A detailed user manual should be available in order to facilitate usage and increase efficiency of the service to the maximum.

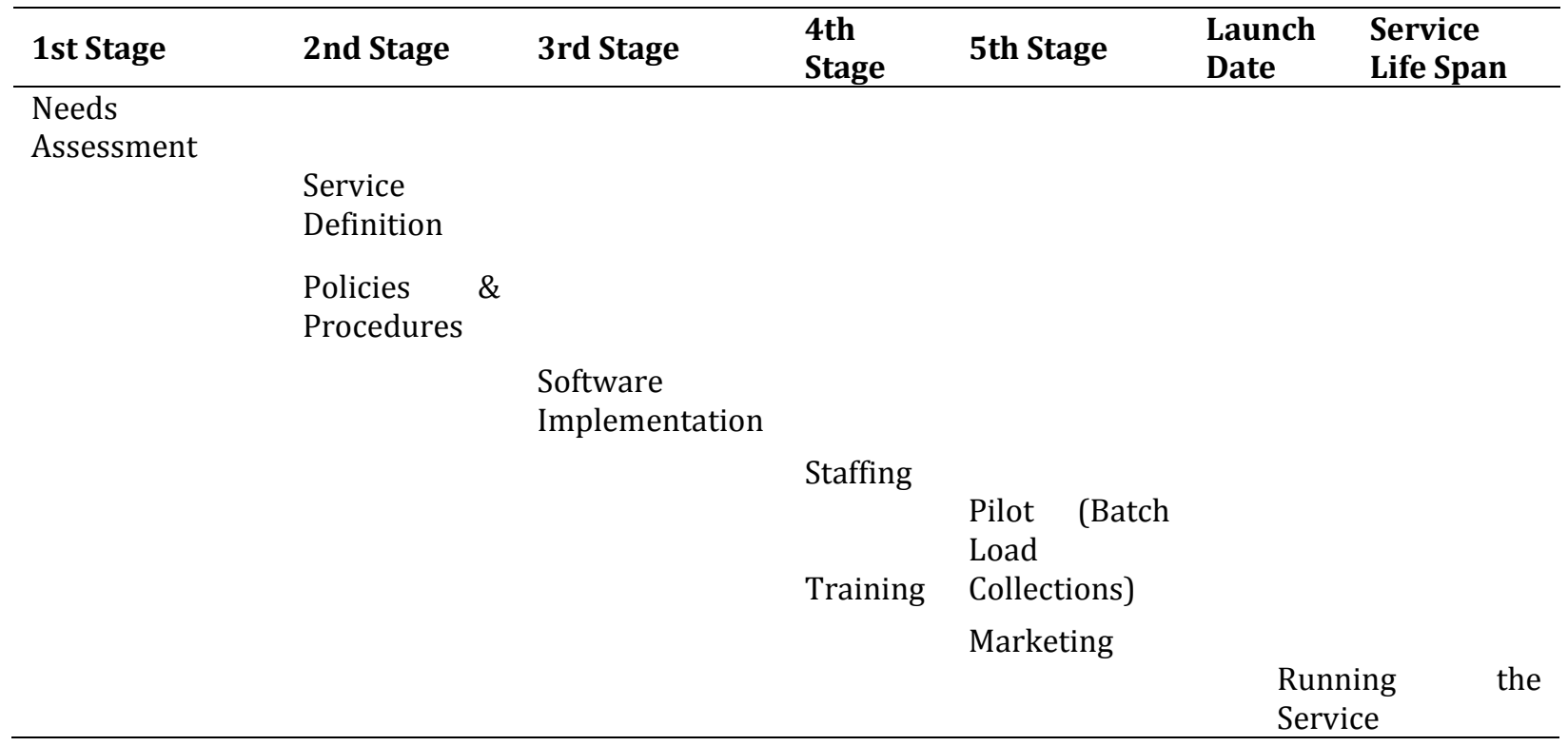

Software Implementation: The project committee should decide on a software platform to house the repository's collections. The committee can adopt one of the open-access databases such as D-space, E-prints, or Fedora; or the IT Librarian will work in collaboration with the Computing and Networking Services on developing in-house software that will be carefully crafted to provide the best organization of collections and better access to information in the repository.

Staffing and Training: An IR Librarian should be hired to manage the service. The IR Librarian will be responsible for developing the service definition; initiating policies and procedures, managing collections; batch loading existing collections in collaboration with the Archives Librarian, the IT Librarian, and the assistance of staff members; as well as managing the service in the long run. $\mathrm{He}$ /she will also be supervising 
staff and assigning work; establishing contact with faculty to encourage them to send their articles and publications to be deposited in the repository; having staff create metadata for items upon depositing them in the repository to facilitate access and retrieval of information; having staff check and requesting copyright permissions when needed and ensuring that copyright laws are not violated; and supporting users either by telephone assistance or online (email, FAQ...). The IR Librarian will be assisted by two library assistants and one clerk. Library assistants will be working on checking copyright permissions, creating metadata and descriptors, and supporting users who request help. The Library Clerk will be preparing documents (ex: scanning, filing, etc.) and depositing them to the repository after entering relevant metadata created by a library assistant and approved by the IR Librarian. Technical problems related to website design, database management, and troubleshooting will be reported to the IT Librarian. More staff may be needed during the implementation phase when batch loading existing collections. The workload should be covered by appointing current library staff to work on the project for a limited period of time. Staff should be introduced to the service and should be fully trained before the launch date. Conferences and workshops will be held by the IR Librarian and guest speakers in order to ensure good preparation of the staff for all functions of the repository.

Running a Pilot Program: When employees are ready and software is fully implemented, the IT Librarian will begin a pilot program in association with the Archives and IT Librarians. The pilot program consists of batch loading existing collections that the committee agrees should be available in the repository such as theses, dissertations, University publications, etc. The committee should also decide on the electronic formats of documents to be loaded into the repository. Some documents may already be available in electronic versions but in different formats, while other documents in print version only need to be scanned. Library assistants and clerks will work under the supervision of the IR and IT Librarians on migrating e-documents from one format to another and scanning print versions and download them into the repository. In addition, the IR Librarian assisted by library assistants will work on creating metadata and descriptors for each document so it can be easily retrieved. After loading existing collections, the database will be available for a number of expert users (Librarians, professors, IT specialists, etc.) for trial. Users will report bugs and problems to the IR Librarian, who will work with the IT Librarian on fixing them and improving retrieval functions.

Marketing: The marketing of the service should begin at the same time as the pilot program. The trial of the service can also be used as a marketing material to introduce faculty to the repository by including them in the trial process so they become aware of the service and its functions. In addition, the IR Librarian will work closely with the Information Services department on crafting marketing materials that include the launching event and others. Marketing materials can include publicizing the repository website, issuing brochures and flyers, organizing workshops for faculty to introduce them to the repository and its services, publishing articles in University newsletters, and others. Librarians should emphasize the benefits of the repository for the academic community in general and faculty members specifically during the marketing campaign. Marketing is a continuous activity that should continue after the launch date and as long as the service is still running.

Running the Service: The repository will be presented to the academic community in the launching event ${ }_{2}$ and the service will start working in the following day. IR employees will apply the procedures that were agreed upon by the committee. Running the service includes many tasks such as loading existing collections, receiving articles, acquiring copyright permissions, creating metadata and descriptors, and depositing the documents into the database. All these tasks should be performed by the IR employees and supervised by the IR Librarian. Marketing is also an ongoing process that should happen every now and then which depends on the popularity of the service.

\section{Conclusion}

Today, as the world is becoming digitized, it is essential to collect and store the important work of research scholars and project staff at the university in digital formats. The Lebanese University has thus far failed to take advantage of the opportunity to support our most innovative and creative University community. Many 
faculty and students have been using the internet as a means for sharing their ideas worldwide, yet our universities have failed to help this group of scholars to disseminate their work. Institutional repositories can contribute to academic communities and a general audience, fields of collection, preservation, and dissemination of the intellectual output of digital research and education material. Furthermore, the era of open and free access to institutional repositories will play a vital role in this process. In addition, the preservation of the publications of the University community in one centralized database is very important in the electronic age where e-documents can be easily lost and access sustainability is not guaranteed. Our university community has been exploring ways in which the new digital medium can enhance teaching, learning and communication. Therefore, it is highly recommended that the University begin the process of building an institutional repository at the University at the earliest possible.

\section{Reference}

Barton, M. \& Waters, M. (2004). Creating an institutional repository: LEADIRS workbook. Available at: http://hdl.handle.net/1721.1/26698

Clifford, A. L. (2003). Institutional Repositories: Essential Infrastructure for Scholarship in the Digital Age: 17. Available at: http://www.arl.org/resources/pubs/br/br226/br226ir.shtml.

Mackie, M. (2004). Filling Institutional Repositories: Practical strategies from the DAEDALUS Project, Ariadne, 39. Available at: http://hdl.handle.net/1905/196

Philip, D. \& Mathew, C. (2007). Institutional repositories: evaluating the reasons for non-use of Cornell University's installation of DSpace, D-Lib Magazine, Volume 13, Number 3/4, and ISSN 1082-9873. Available at: http://works.bepress.com/cgi/viewcontent.cgi?article=1007\&context=ir_research

Shulenburger, D. (2008). SPARC Digital Repositories Meeting 2008, Closing Keynote. Available at: http://www.arl.org/sparc/bm doc/shulen_trans.pdf

Stanger, N. \& McGregor, G. (2007). EPrints make its mark, OCLC Systems \& Services. International Digital Library Perspectives, 23(2), 133-141.

Cohen, S. \& Deborah, S. (2007). Creating a Multipurpose Digital Institutional Repository, OCLC Systems \& Services, International Digital Library Perspectives 23(3), p287-296, Available at: http://works.bepress.com/suzanne_cohen/1/. 